\title{
Growth of Rumen Bacteria on Plant Cell Wall Polysaccharides
}

\author{
By R. T. J. CLARKE, R. W. BAILEY AND \\ BLANCHE D. E. GAILLARD \\ Plant Chemistry Division, Department of Scientific and Industrial \\ Research, Palmerston North, New Zealand
}

(Accepted for publication 2 December I968)

\begin{abstract}
SUMMARY
Three strains of Butyrivibrio fibrisolvens were isolated from the rumen contents of cattle feeding on red (Trifolium pratense L.) or white (T. repens L.) clover. The substrates used in these isolations were plant hemicellulose fractions other than simple insoluble xylan. The strains showed some differences in their ability to grow on various plant polysaccharides and to secrete polysaccharases specific to these polymers. The same type of rumen contents yielded, on polygalacturonic acid media, a strain of Lachnospira multiparus which grew only on pectin and secreted as sole polysaccharase a polygalacturonase. Only one of the three $B$. fibrisolvens strains grew vigorously on polygalacturonic acid and its polygalacturonase appeared to be different to that of the L. multiparus.
\end{abstract}

\section{INTRODUCTION}

The main polysaccharides of pasture plant cell walls are cellulose and xylan and many studies have been made on the action of rumen bacteria on these compounds. Thus strains of Butyrivibrio fibrisolvens, Bacteroides succinogenes, B. ruminocola, Ruminococcus spp. and Clostridium lochheadii from the rumen have been shown to utilize one or both of these polymers (see Hungate, 1966). Other polysaccharides associated with plant cell walls, but usually present in smaller amounts, include pectin and polymers containing galactose, mannose, rhamnose and uronic acids as well as the pentoses, arabinose and xylose. The insoluble xylan commonly used in the isolation of rumen hemicellulose fermenters lacks, for instance, the complex galactose-rich branched, hemicellulose-B type polymers and it is likely that previous isolations of xylan-fermenting bacteria have missed fermenters of 'branched-B' type polysaccharides. The action of rumen bacteria on these latter compounds does not appear to have been investigated to any extent except in studies using preparations of mixed bacteria (Gaillard, Bailey \& Clarke, 1965). We have now prepared galactose-rich fractions ('branched-B' hemicellulose of Gaillard, 1965) from clover and grass in sufficient amounts for cultural studies and, using media containing these polysaccharide fractions, we have isolated bacteria from the rumens of cattle. Bacteria have also been isolated from similar rumen contents using media containing free pentose and pectin polygalacturonic acid respectively.

The bacterial strains growing on these hemicellulose fractions would be expected to produce a mixture of extra- or intracellular carbohydrases capable of hydrolysing each polysaccharide. The mixture of carbohydrases produced is of interest not only in understanding the bacterial breakdown of the polymers, but also as a possible tool in 
examining polysaccharide structure. The fermentation properties, occurrence of intracellular carbohydrases and other characteristics of these bacteria have, therefore, been examined and form the subject of this paper.

\section{METHODS}

Animals. Two dry cows fitted with permanent rumen cannulae were used. One cow (no. 35) was stall-fed red clover (Trifolium pratense L.) hay, while the other (no. 5I) grazed a pasture of mixed ryegrass (Lolium perenne L.) + white clover (T. repens L.).

Carbohydrates. Monosaccharides, disaccharides and soluble starch were the usual commercial sugars. Laminarin, larch galactan, lichenin, araban and polygalacturonic acid (P.G.A.) were from Koch-Light Ltd. Insoluble xylan was from Mann Research Laboratories, New York, citrus pectin from Sigma Chemical Co., St Louis, U.S.A., and guaran from an unknown commercial source. Isolichenin was donated by Dr D. H. Hutson. Finely ground cellulose was prepared from cotton wool by the pebblemilling technique of Hungate (1950). Wheat flour pentosan (water soluble arabinoxylan) was prepared from wheat flour (Howard, 1957), barley $\beta$-glucan from barley meal (Parrish, Perlin \& Reese, I960) and lupin galactan from blue lupin seeds (Hirst, Jones \& Walder, 1947). Chromatograms of acid hydrolysates $\left(\mathrm{N}^{-} \mathrm{H}_{2} \mathrm{SO}_{4}, 2 \mathrm{hr}, 100^{\circ}\right)$ of the two latter polysaccharides showed the presence of small amounts ( $\mathrm{I}$ to $2 \%$ ) of pentoses as well as the expected glucose or galactose. A similar acid hydrolysate of the polygalacturonic acid showed no sign of any neutral sugars but a hydrolysate of the citrus pectin contained both galactose and arabinose (estimated $\ngtr 1$ to $2 \%$ ).

Hemicellulose fractions were prepared from ryegrass (L. perenne L.) leaves, corn (Zea mais L.) stems and red clover ( $T$. pratense L.) stems as follows. Ground, freezedried plant tissue was extracted either by successively boiling with ethanol $(80 \%$, $\mathrm{v} / \mathrm{v})$, water and ammonium oxalate $(0.5 \%, \mathrm{w} / \mathrm{v})$ or by boiling with neutral detergent (Gaillard, I966) to give a cell wall (hemicellulose + cellulose + lignin) residue. Hemicellulose was dissolved from this residue by overnight extraction with potassium hydroxide under nitrogen (10\%,w/v). Hemicellulose-A xylan was removed from the I0 \% KOH filtrate by acidification with acetic acid to $\mathrm{pH} 4.5$ and centrifugation, after which the supernatant was dialysed and freeze-dried to give hemicellulose-B. This hemicellulose-B was fractionated (Gaillard, I965) by dissolving in strong (S.G. I·3) calcium chloride and treating with iodine-potassium iodide solution to give ultimately 'linear-B' arabino-xylan and 'branched-B' heteroglycan. (The monosaccharide compositions of these fractions are given in Table 3.)

Bacteria. Bacteria were isolated from rumen contents by the anaerobic method of Hungate (1950). All manipulations were done in a stream of $\mathrm{CO}_{2}$ freed of $\mathrm{O}_{2}$ by passage over reduced copper turnings at $460^{\circ}$. Inoculation of the original roll-tube series and subsequent transfers were made through the rubber bung with I ml. hypodermic syringes.

The medium used for isolation, growth and subsequent maintenance of the isolates had the following composition: mineral salt solution, Io $\mathrm{ml}$; centrifuged rumen fluid, $20 \mathrm{ml}$.; distilled water, $70 \mathrm{ml}$; $\mathrm{NaHCO}_{3}, 0.5 \mathrm{~g}$.; cysteine- $\mathrm{HCl}, 0.02 \mathrm{~g}$.; resazurin, $0.00 \mathrm{I} \mathrm{g}$.; $\left(\mathrm{NH}_{4}\right)_{2} \mathrm{SO}_{4}$, 0.I g.; tryptone (Difco), 0.I g. Specific carbohydrates, 0.05-0. Io g. were added to this basic medium and agar, $I \cdot I \%(w / v)$, was added when required. The salt solution contained (g./IOO ml.): $\mathrm{K}_{2} \mathrm{HPO}_{4}, \mathrm{I} \cdot 5 \mathrm{~g}$.; $\mathrm{NaCl}, 6 \cdot 0 \mathrm{~g}$.; $\mathrm{MgSO}_{4} \cdot 7 \mathrm{H}_{2} \mathrm{O}$, 
$0.05 \mathrm{~g}$.; $\mathrm{CaCl}_{2}, 0.05 \mathrm{~g}$. Centrifuged rumen fluid was obtained by centrifuging strained rumen contents for $20 \mathrm{~min}$. at $10,000 \mathrm{~g}$.

Maintenance of cultures. Cultures in current use were maintained on the medium on which they were isolated, subculturing being carried out every 3 days. Stock cultures were maintained on agar at $-70^{\circ}$.

Fermentation of carbohydrates. The basal medium was the same as that used for the isolation of the bacteria. Fermentation of the carbohydrate substrates was tested in the basal medium with $0.05 \%(\mathrm{w} / \mathrm{v})$ added carbohydrate. The inoculum for each test was one drop of a $24 \mathrm{hr}$ culture in the basic liquid medium with glucose. Growth was assessed after 24 and $48 \mathrm{hr}$ incubation at $37^{\circ}$.

Fermentation products. Cultures for fermentation analysis were grown in $150 \mathrm{ml}$. medium (250 ml. round-bottomed flasks) under an atmosphere of $100 \% \mathrm{CO}_{2}$. The medium used was the basic medium with $0 \cdot \mathrm{I} \%(\mathrm{w} / \mathrm{v})$ glucose as carbon source. After incubation for $48 \mathrm{hr}$ the cells were removed by centrifugation and the medium deproteinized by precipitation with $\mathrm{ZnSO}_{4}$ and $\mathrm{Ba}(\mathrm{OH})_{2}$.

Volatile fatty acids were quantitatively determined after steam distillation in a Markham (1942) apparatus by both gas-liquid chromatography on the apparatus of James \& Martin (1952) and column partition chromatography on Celite (Swim \& Utter, 1957). Lactic acid was measured by the colorimetric method of Barker \& Summerson (I94I). A mixture of lactic and succinic acids was also separated by chromatography on celite and after measuring lactic acid in the mixture the succinic acid concentration obtained by difference. Ethanol was determined by Conway's (1957). micro-diffusion method

Bacterial extracts. Bacterial cells from cultures $(500 \mathrm{ml}$.) grown in I 1. round-bottom flasks were harvested by centrifugation $(20,000 \mathrm{~g})$ and disrupted with Ballotini beads (no. I4) in citrate buffer (O. I M, pH 6.0) in a Nossal (I953) shaker. After removal of cell debris by centrifugation $(20,000 \mathrm{~g})$ the supernatant $(5$ to $10 \mathrm{ml}$. from 2 to $5 \mathrm{~g}$. wet wt of cells) was dialysed at $0^{\circ}$ for $24 \mathrm{hr}$ against the same citrate buffer. A portion of the centrifuged, cell-free culture fluid was also similarly dialysed.

Carbohydrase activity. Enzyme digests containing bacterial extract $(0.2 \mathrm{ml}$.) or dialysed cell-free culture fluid ( $0.5 \mathrm{ml}$.), citrate buffer (0.1 $\mathrm{M}, \mathrm{pH} 6.0,0.2 \mathrm{ml}$.) and polysaccharide ( 2 to $4 \mathrm{mg}$.) were incubated for $24 \mathrm{hr}$ at $37^{\circ}$ under toluene and then analysed for liberated sugars by paper chromatography. Chromatograms were developed with ethyl acetate + water + pyridine $(2+2+1)$ and sprayed with aniline hydrogen phosphate (Howard, 1957) reagent.

\section{RESULTS}

\section{Characterization of the isolates cultured}

Four anaerobic bacteria (PC/IOI, IO2, 103 and I04) were isolated on four substrates (arabinose, corn 'branched-B', clover 'branched-B' and P.G.A.). These bacteria were the only ones which grew on the substrates used, although only one attempt was made to isolate bacteria on each substrate. The characteristics of the bacteria isolated are given below. The standard fermentation reactions are shown in Table $\mathrm{I}$.

Isolate PC/IOI. This organism was isolated from cow 35 at a dilution of $10^{-8}$ on a medium containing arabinose. It was a Gram-negative, motile, curved rod, $\mathrm{I} \cdot \mathrm{O}$ to $3.5 \mu \times 0.5 \mu$, occurring singly, in pairs and short chains. In arabinose roll-tubes it 
grew as a diffuse, rhizoid colony, 0.5 to $1.0 \mathrm{~mm}$. in diameter. Growth in arabinose or glucose liquid medium was in the form of a flocculent sediment.

Glucose was fermented with the production of gas and butyric, acetic, formic and lactic acids in the ratio $2: 1: 2: 3$.

Isolate $\mathrm{PC} /$ ro4. This organism was isolated from cow 35 at a dilution of $1 \mathrm{O}^{-8}$ on a medium containing 'branched-B' heteroglycan from corn. It was a Gram-negative, motile, curved rod, similar to isolate $\mathrm{PC} / \mathrm{IO} 2$ and measured I $\cdot 0$ to $3.5 \mu \times 0.5 \mu$. Growth in xylan or glucose liquid medium was in the form of small ropey clumps which flocculated as the culture aged.

\section{Table I. Carbohydrates fermented by strains of rumen bacteria}

A positive sign indicates that growth occurred. A negative sign indicates that no growth occurred. All strains failed to grow on lactic acid, mannitol and glycerol.

\begin{tabular}{|c|c|c|c|c|}
\hline \multirow[b]{2}{*}{ Carbohydrate } & \multicolumn{4}{|c|}{ Bacterial isolates } \\
\hline & PC/IOI & PC/IO4 & $\mathrm{PC} / 103$ & $\mathrm{PC} / \mathrm{IO2}$ \\
\hline Glucose & + & + & + & + \\
\hline Galactose & + & + & + & - \\
\hline Maltose & + & + & + & - \\
\hline Mannose & + & - & + & - \\
\hline Xylose & + & + & + & - \\
\hline Arabinose & + & + & + & - \\
\hline Fructose & + & + & + & + \\
\hline Sucrose & + & + & + & + \\
\hline Cellobiose & + & + & + & + \\
\hline Melibiose & + & + & + & - \\
\hline Starch & + & + & + & - \\
\hline
\end{tabular}

Glucose was fermented with the production of gas, and volatile acid, predominately butyric. A small amount of lactic acid was also produced.

Isolate $P C /$ I03. This organism was isolated from cow $5 \mathrm{I}$ at a dilution of $10^{-8}$ on a medium containing 'branched-B' heteroglycan from red clover. It was a Gramnegative, motile, curved rod, $\mathrm{I} \cdot 0$ to $3.7 \mu \times 0.5 \mu$, occurring singly, in pairs and chains up to $60 \mu$ in length. Growth in xylan liquid medium was flocculent.

Butyric acid together with acetic, formic and lactic acids, was produced from glucose. A small amount of gas was also produced.

Isolate PC/IO2. This organism was isolated from cow 35 at a dilution of $10^{-9}$ on a medium containing polygalacturonic acid (P.G.A.). It was a weakly Gram-positive, motile rod, usually curved, $\mathrm{I} \cdot 5$ to $3 \cdot 0 \mu \times 0.3 \mu$, occurring singly and in pairs with occasional long chains. Colonies on glucose agar were filamentous and about $1 \mathrm{~mm}$. in diameter. The end-products produced from glucose were predominantly acetic and lactic acids. Propionic and succinic acids were not produced. Some $\mathrm{CO}_{2}$ was formed.

\section{Identity of the isolates cultured}

Isolates PC/IOI, I03, IO4 which were morphologically identical were identified as strains of Butyrivibrio fibrisolvens (Bryant \& Small, 1956a). All strains produced butyric, acetic, formic and lactic acids, the proportions varying with each strain but butyric acid always being produced in large amounts. The standard carbohydrate 
fermentation pattern of each strain was the same except that isolate PC/IO4 did not ferment mannose.

Isolate PC/IO2 was identified as a strain of Lachnospira multiparus (Bryant \& Small, $1956 b$ ) differing from the type strain in that acetic acid was the major product and only traces of formic acid and ethanol were formed.

Growth of the isolated bacteria on polysaccharides. Each organism was inoculated into tubes of the standard medium containing various plant polysaccharides as carbohydrate source. After incubation for $48 \mathrm{hr}$ at $37^{\circ}$ growth was assessed visually. The results obtained are summarized in Table 2.

\section{Table 2. Growth of isolated rumen bacteria on plant polysaccharides}

Standard media contained added polysaccharide $(0.05 \%)$ and inoculated tubes were incubated for $48 \mathrm{hr}$ at $37^{\circ}$. Growth was graded on the basis of: -, no growth; \pm , doubtful growth;,+++ , moderate and heavy growth respectively; n.t., not tested because of lack of substrate.

\begin{tabular}{lcccc}
\multicolumn{1}{c}{ Polysaccharide } & PC/10I & PC/IO4 & PC/103 & PC/IO2 \\
Xylan & ++ & ++ & ++ & - \\
Wheat flour pentosan & ++ & ++ & ++ & - \\
Grass 'branched-B' heteroglycan & ++ & ++ & n.t. & - \\
Clover 'branched-B' heteroglycan & n.t. & + & ++ & - \\
Laminarin & \pm & - & - & - \\
Lichenin & - & + & ++ & \pm \\
Barley $\beta$-glucan & $(+)^{*}$ & $(++)^{*}$ & ++ & - \\
Cellulose & - & - & - & - \\
Lupin galactan & \pm & + & + & - \\
Larch galactan & + & + & - & - \\
Guaran & - & - & + & - \\
Polygalacturonic acid & - & - & ++ & ++
\end{tabular}

* Possibly growth on pentosan impurity.

\section{Hydrolysis of polysaccharides by bacterial extracts and culture fluids}

Cell extracts prepared from the organisms grown on various carbohydrates were tested for polysaccharase activity against a range of plant polysaccharides. The results are summarized in Table 3 . With one exception the carbohydrase activity demonstrated involved the liberation of monosaccharides by cell extracts prepared from cells harvested and disrupted without any attempt to exclude oxygen. The exception was the polygalacturonase activity of Butyrivibrio fibrisolvens (PC/103). While chromatograms of digests containing P.G.A. and cell extract from Lachnospira multiparus (strain PC/102) showed a strong spot corresponding to galacturonic acid indicative of polygalacturonase this was not the case with similar extracts of the butyrivibrio. When the butyrivibrios were, however, harvested with the exclusion of oxygen and incubated intact under toluene with P.G.A. galacturonic acid was liberated. No sign of such a hydrolysis could be obtained with extracts or cell-free culture fluid even though the organisms were extracted as far as possible in the absence of oxygen. A digest containing P.G.A. with culture fluid, extract and debris combined did, however, show the liberation of a possible digalacturonic acid but no free galacturonic acid.

Dialysed cell-free culture fluids from the cultures were also tested for polysaccharase 

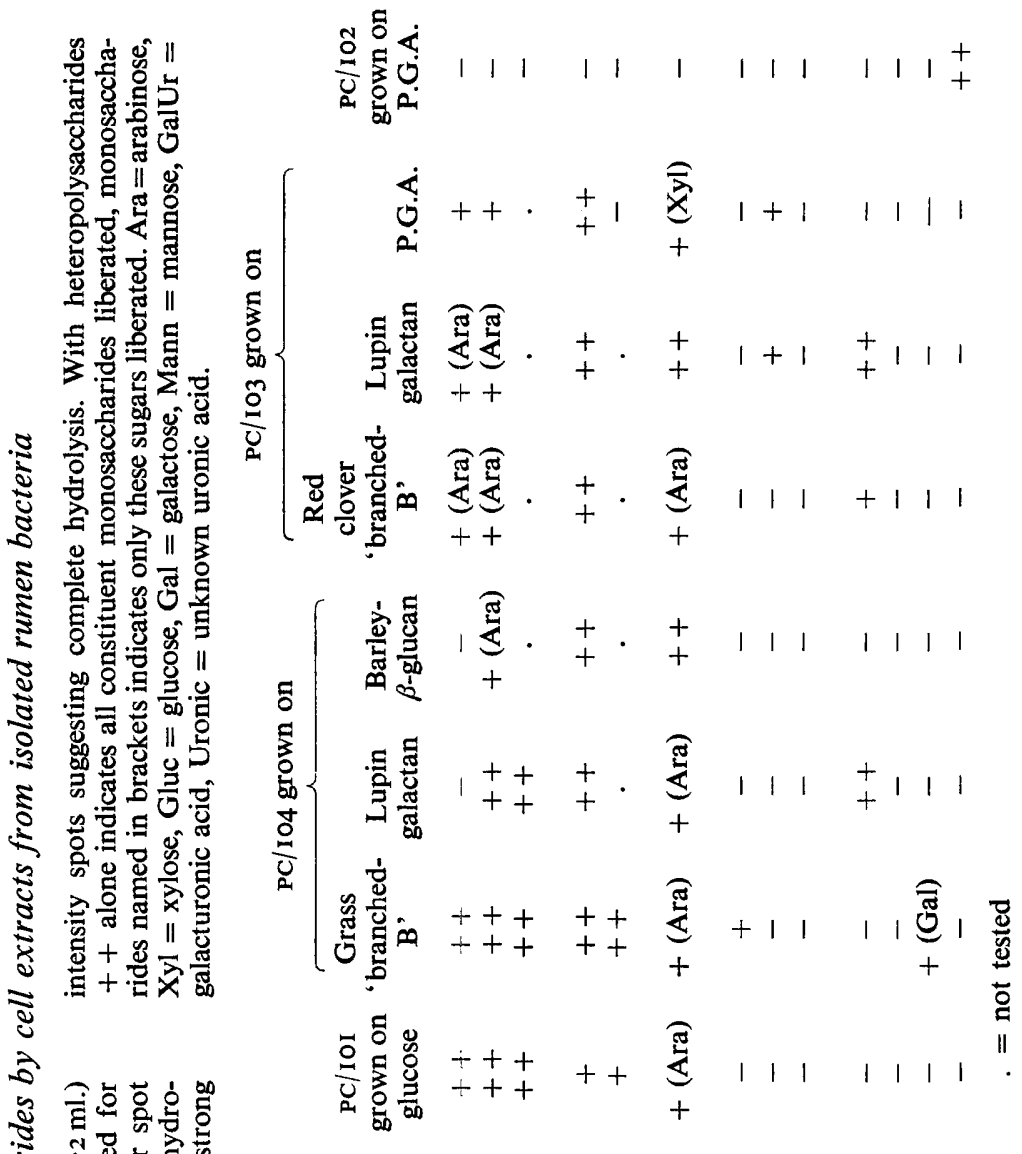

¿

원

ठ ส

¿

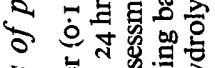

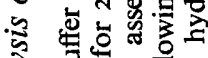

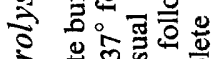

ま

¿

$\dot{m}$ 产

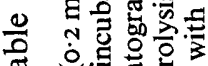

๘

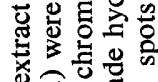

于

on 영욜

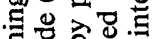

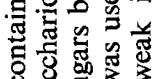

800

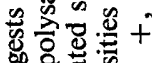

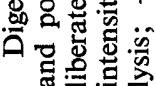
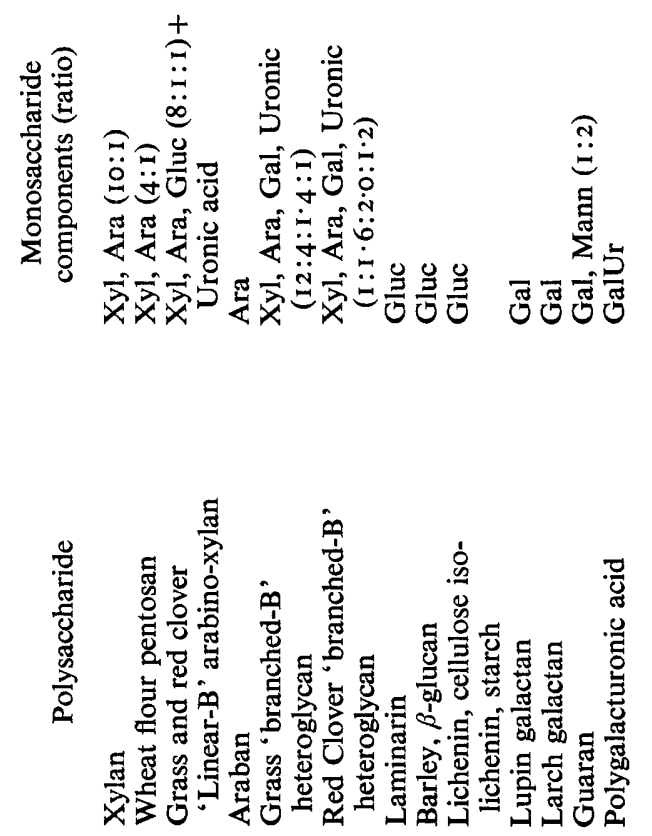
activities. Apart from an occasional liberation of trace amounts of arabinose (from araban and arabino-xylan) these culture fluids did not liberate any mono- or oligosaccharides from the polysaccharides. Enzyme results appeared anomalous in one case. Although organisms PC/IOI and PC/IO4 appeared to grow on barley $\beta$-glucan the extracts liberated pentoses but no glucose from this polysaccharide suggesting that these organisms were only growing on the pentosan impurity.

\section{DISCUSSION}

Although an exhaustive search for fermenters of hemicellulose 'branched-B' was not made, the fact that the only two isolates obtained on hemicellulose 'branched-B' in the present work were strains of Butyrivibrio fibrisolvens, an organism commonly isolated on xylan, suggests that there is no specific fermenter of the 'branched-B' polymer and that its fermentation is shared among the common xylan fermenting species. Growth of the three $B$. fibrisolvens strains on various polysaccharides and the activities of the polysaccharases extracted from them do, however, point to strain differences. It may be, therefore, that some strains of $B$. fibrisolvens are better able to attack the 'branched- $B$ ' polysaccharide than many of the xylan-fermenting strains. It is perhaps relevant to the xylan-fermenting abilities of $B$. fibrisolvens that the three strains always produce pentosanases regardless of the substrate they are grown on, whereas the production of enzymes hydrolysing seed galactan required growth on this polysaccharide.

Pectin is closely associated with hemicellulose and rumen bacteria able to ferment pectin include strains of Bacteroides succinogenes, B. ruminicola, Butyrivibrio fibrisolvens, Succinivibrio dextrinosolvens and Lachnospira multiparus (see Hungate, 1966). Of these organisms L. multiparus has been observed (Bryant et al., I960) to be abundant in the rumens of cattle fed on legume forages which contain more pectin than grasses, so that it was not surprising that the rumen contents of our cow, fed clover containing 5 to $6 \%$ pectin, yielded on the P.G.A. substrate a strain of $L$. multiparus. Carbohydrate, enzyme and growth studies suggest that the strain was highly specific for pectin with a normal polygalacturonase. The only one of the three Butyrivibrio isolates which grew on the P.G.A. was that (PC/IO3) isolated on the uronic acid-rich hemicellulose 'branched-B' from clover. Growth of this organism on P.G.A. was luxuriant after $48 \mathrm{hr}$ but the pectinases appeared to be different to the Lachnospira polygalacturonase particularly in being difficult to extract.

The present study of hemicellulose fermentation has been confined to four rumen bacteria isolated on media containing specific carbohydrates, these being the only bacteria isolated on these substrates at a single attempt. Other studies have shown that rumen bacteria isolated for example on cellulose (Dehority, 1967) are able to hydrolyse xylan and it may well be that some of these organisms can ferment plant hemicellulose 'branched-B' type polysaccharides. It is likely though that the bacteria isolated directly from the rumen contents using specific carbohydrate substrates are those most actively responsible for the breakdown of these substrates in the rumen. Butyrivibrio fibrisolvens has long been accepted as an important organism in the rumens of cattle, particularly with regard to the fermentation of xylan (Hungate, 1966). That it was the only organism isolated on the 'branched-B' fractions is significant from this point of view. The differences in substrate specificity between the three strains studied 
are significant with regard to the highly successful adaptation of a single species to fill several niches in a complex nutritional environment.

The technical assistance of Mr G. Naylor is acknowledged. One of the authors B.D.E.G. was a visiting research worker from the Animal Physiology Department, The University, Wageningen, The Netherlands.

\section{REFERENCES}

BARKER, S. W. \& SUMmerson, W. H. (194I). The colorimetric determination of lactic acid in biological material. J. biol. Chem. 138, 535.

BRYANT, M. P. \& SMall, N. (1956a). The anaerobic monotrichous butyric acid-producing rod-shaped bacteria of the rumen. J. Bact. 72, 16.

Bryant, M. P. \& SMall, N. (I956b). Characteristics of two new genera of anaerobic curved rods isolated from the rumen of cattle. J. Bact. 72, 22.

Bryant, M. P., Barrentine, B. F., Sykes, J. F., Robinson, I. M., Shawver, C. V. \& Williams, L. W. (I960). Predominant bacteria in the rumen of cattle on bloat provoking ladino clover pasture. J. Dairy Sci. 43, 1435.

Conway, E. J. (1957). Microdiffusion Analysis and Volumetric Error, 4th ed. (rev.). London: Crosby Lockwood and Son Ltd.

DEHORITY, B. A. (1967). Rate of isolated hemicellulose degradation and utilization by pure cultures of rumen bacteria. J. appl. Microbiol. 15, 987.

GaILLARD, B. D. E. (1965). Comparison of the hemicelluloses from plants belonging to two different plant families. Phytochemistry 4, 631 .

GaILlaRD, B. D. E. (1966). Calculation of the digestibility for ruminants of roughages from the contents of cell wall constituents. Neth. J. Agric. Sci. 14, 215.

Gaillard, B. D. E., Bailey, R. W. \& Clarke, R. T. J. (1965). The action of rumen bacterial hemicellulases on pasture plant hemicellulose fractions. J. agric. Sci. 64, 449.

HIRST, E. L., JoNES, J. K. N. \& WALDER, W. O. (I947). The constitution of the galactan from Lupinus albus seeds. J. chem. Soc. p. 1225.

HowARD, B. H. (1957). Hydrolysis of the soluble pentosans of wheat flour and Rhodymenia palmata by ruminant micro-organisms. Biochem. J. 67, 643 .

Hungate, R. E. (1950). The anaerobic mesophilic cellulolytic bacteria. Bact. Rev. 14, I.

Hungate, R. E. (1966). The Rumen and its Microbes, p. 70. London and New York: Academic Press.

JAMES, A. T. \& MARTIN, A. J. P. (1952). Gas-liquid partition chromatography: the separation and micro-estimation of volatile fatty acids from formic acid to dodecanoic acid. Biochem. J. 50, 679.

MARKHAM, R. (1942). A steam distillation apparatus suitable for micro-Kjeldahl analysis. Biochem. J. 36, 790 .

Nossal, P. M. (1953). A mechanical cell disintegrator. Aust. J. exp. Biol. med. Sci. 31, 583.

Parrish, F. W., Perlin, A. S. \& Reese, E. T. (1960). Selective enzymolysis of poly- $\beta$-D-glucans and the structure of the polymers. Can. J. Chem. 38, 2094.

SWIM, H. E. \& UTTER, M. F. (1957). Isotopic experimentation with intermed iates of the tricarboyxlic acid cycle. Meth. Enzymol. 4, 584. 